\title{
Erratum to: A comprehensive procedure for antiviral inhibitor discovery using EV71 as an example
}

\author{
Lin Cao' ${ }^{1}$, Shouhai Zhu' ${ }^{1}$, Yaxin Wang ${ }^{2}$, Zhiyong Lou ${ }^{3}$, Yuna Sun ${ }^{2 \bowtie}$ \\ ${ }^{1}$ College of Biotechnology, Tianjin University of Science and Technology, Tianjin 300457, China \\ 2 National Laboratory of Macromolecules, Institute of Biophysics, Chinese Academy of Science, Beijing 100101, \\ China \\ 3 Laboratory of Structural Biology, School of Medicine, Tsinghua University, Beijing 100084, China
}

Published online: 20 January 2016

ERRATUM TO: BIOPHYS REP

DOI 10.1007/S41048-015-0006-Z

The authors would like to request the addition in the end of the legend of Fig. 7 "(modified from Qing et al. 2014)" and the addition of the correct reference "Qing J,
Wang Y, Sun Y, Huang J, Yan W, Wang J, Su D, Ni C, Li J, Rao Z, Liu L, Lou Z (2014) Cyclophilin A associates with enterovirus-71 virus capsid and plays an essential role in viral infection as an uncoating regulator. PLoS Pathog 10(10):e1004422. doi:10.1371/journal.ppat.1004422. eCollection 2014 Oct." in the Reference list.

The online version of the original article can be found under doi:10.1007/s41048-015-0006-z.

$\bowtie$ Correspondence: sunyn@moon.ibp.ac.cn (Y. Sun) 